Food and Bioprocess Technology

September 2008, Volume 1, Number 3 : Pages 297-

300

http://dx.doi.org/10.1007/s11947-008-0082-x

(c) 2008 Springer. Part of Springer Science+Business

Media

The original publication is available at http://www.springerlink.com
Archimer, archive institutionnelle de l'Ifremer http://www.ifremer.fr/docelec/

\title{
A New Process for Extracting Alginates from Laminaria digitata : Reactive Extrusion
}

\author{
Peggy Vauchel ${ }^{1,}{ }^{*}$, Raymond Kaas ${ }^{2}$, Abdellah Arhaliass ${ }^{1}$, Régis Baron ${ }^{3}$ and Jack Legrand ${ }^{1}$ \\ ${ }^{1}$ GEPEA, CNRS, Université de Nantes, UMR 6144, CRTT, BP406, 37 bd de l'Université, 44602 Saint-Nazaire \\ Cedex, France \\ ${ }^{2}$ Laboratoire Physiologie et Biotechnologie des Algues, IFREMER, rue de l'lle d'Yeu, BP21105, 44311 Nantes \\ Cedex 03, France \\ ${ }^{3}$ Département Sciences et Techniques Alimentaires Marines, IFREMER, rue de l'lle d'Yeu, BP21105, 44311 \\ Nantes Cedex 03, France \\ *: Corresponding author : P. Vauchel, tel : 00332401726 31, fax : 00332401726 18, email address :
peggy.vauchel@univ-nantes.fr
}

\begin{abstract}
:
Alginates are natural polysaccharides that are extracted from brown seaweeds and widely used for their rheological properties. The main step in the extraction protocol used in the alginate industry is that of alkaline extraction. A batch process is used for this step, which is time-, water-, and reactantconsuming. The possibility of extracting by reactive extrusion was investigated. The reactive extrusion process appeared to be more efficient than the batch process for the alkaline extraction of alginates from Laminaria digitata in several key ways: Time demand is reduced from about an hour to only few minutes, water and reactant requirements are divided by more than a factor 2, extraction yield is $15 \%$ higher (relative enhancement), and the rheological properties of the product were all enhanced. Hence, reactive extrusion could be an interesting alternative process for the alginate industry to produce high rheological properties alginates.
\end{abstract}

Keywords: Alginate - Alkaline extraction - Laminaria digitata - Reactive extrusion - Intrinsic viscosity 


\section{Introduction}

Alginates are naturally present in the cell walls of brown seaweeds (Kloareg \& Quatrano, 1988). These polysaccharides show interesting rheological properties and are widely used in various fields of industry, including textiles, agri-foods, paper, cosmetics, and pharmaceuticals (Pérez et al., 1992). The alginate industry extraction protocol is divided into five steps: acidification, alkaline extraction, solid/liquid separation, precipitation and drying (Pérez, 1997). Alkaline extraction is the main step as it corresponds to the extraction phase itself. Acidified seaweeds are immersed in a sodium carbonate solution: insoluble alginic acid is converted into soluble sodium alginate, which passes into the aqueous phase. This step, which is conducted in a batch reactor, requires high quantities of reactant and water, and several hours are required to attain the optimum extraction yield, depending on the seaweed species concerned (Pérez, 1997). The alkaline extraction time is thought to influence the rheological properties of alginates: the reaction conditions seem to favor bacterial development and endogenous alginate lyase activity, the likely cause of alginate degradation (Moen et al., 1997; Smidsrød et al., 1963). Shortening alkaline extraction time whilst still producing alginate of high rheological quality would undoubtedly be of interest to the alginate industry.

This paper presents our evaluation of reactive extrusion as a new process for the alkaline extraction of alginates from Laminaria digitata. We undertook a comparative study of both classical batch extraction and reactive extrusion extraction, taking into account several significant points: extraction yield, reactant and water consumption, alginate quality (purity and rheological properties) and the time required.

\section{Materials and methods}

\section{Biological material}

All experiments were conducted on two-year-old Laminaria digitata fronds harvested in Portsall, Brittany, France. The entire fronds were cut into small pieces $\left(5 \mathrm{~mm}^{2}-5 \mathrm{~cm}^{2}\right)$ by means of a separator (RM70S type provided by LIMA S.A.S., Quimper, France). This range corresponds to the algae pieces size used in the industry. Algae pieces from all parts of all fronds were mixed in order to minimize heterogeneity problems like variation in alginate content as a function of the frond and as a function of which part of the frond the pieces came from (Pérez, 1970), and stored in a $2 \%(\mathrm{w} / \mathrm{w})$ formalin solution to ensure their preservation during stocking (about 4 months).

Alginate extraction experiments

The extraction protocol was a laboratory adaptation of the industrial process described by Pérez et al. (1992).

\section{Acidification}

Before each extraction experiment (batch extraction and reactive extrusion extraction), algae pieces were rinsed with distilled water in order to eliminate any formalin present, immersed in a $0.5 \mathrm{M} \mathrm{H}_{2} \mathrm{SO}_{4}$ solution for at least one night (stored at $4^{\circ} \mathrm{C}$ ), and rinsed again with distilled water to eliminate acid excess.

\section{Batch alkaline extraction}

For each batch extraction experiment, $200 \mathrm{~g}$ of acidified algae pieces were soaked in $1 \mathrm{~L}$ of a $4 \%(\mathrm{w} / \mathrm{w}) \mathrm{Na}_{2} \mathrm{CO}_{3}$ solution and subjected to continuous stirring. A magnetic bar stirring system has been used $(12 \mathrm{~cm}$ diameter $2 \mathrm{~L}$ beaker with a $4 \mathrm{~cm}$ long magnetic stirrer) as it provides a good simulation of industrial stirring systems. Samples were taken every 30 minutes in order to determine extraction yield until its maximum value was attained (3 consecutive equal values). 


\section{Reactive extrusion alkaline extraction}

Reactive extrusion experiments were conducted on a corotative twin-screw extruder (BC21 type provided by Clextral, Firminy, France). A simple screw profile, composed of decreasing direct pitch screw elements and a small reverse screw element (Figure 1) and a $4 \mathrm{~mm}$ diameter and $5 \mathrm{~cm}$ long cylindrical die were used. Algae pieces were introduced to the hopper, and the feed rate was regulated by means of a feed pump. An external volumetric pump was used to supply the extruder with a $4 \%$ (w/w) $\mathrm{Na}_{2} \mathrm{CO}_{3}$ solution (Figure 1). As alginate starts to degrade at $40^{\circ} \mathrm{C}$, the barrel temperature was maintained at $20^{\circ} \mathrm{C}$.

\section{Solid/liquid separation}

For both batch extraction and reactive extrusion samples, algae residues were separated from sodium alginate solution by centrifugation $\left(10000 \mathrm{~g} ; 10 \mathrm{~min} ; 10^{\circ} \mathrm{C}\right)$. Sodium alginate solutions were stored at $4^{\circ} \mathrm{C}$.

\section{Precipitation and drying}

Sulphuric acid was added to sodium alginate solution $(\mathrm{pH}=2)$ so as to form alginic acid, which precipitates forming foam. The product was afterwards pressed manually through a filter cloth, heat-dried (in a drying oven at $30^{\circ} \mathrm{C}$ ), milled by means of a pestle and mortar, and stored at $4^{\circ} \mathrm{C}$.

\section{Determination of extraction yield}

The sodium alginate content of the centrifugation supernatent was quantified according to the method used by Kennedy \& Bradshaw (1984). This method is based on the polyhexamethylbiguanidium chloride (PHMB) ability to precipitate sodium alginate. It consists of a back titration. PHMB is added to the sodium alginate sample in excess so as to ensure a total reaction and PHMB excess is quantified by UV spectrophotometry (at $235 \mathrm{~nm}$ ). Polyhexamethylenebiguanidium chloride solution was supplied by Bayrol France S.A. and sodium alginate used for the calibration curve was supplied by Sigma-Aldrich Chemie S.A.R.L. (Saint-Quentin Fallavier, France). The extraction yield was calculated as the ratio of the dry weight of alginic acid extracted to the dry weight of algae used for the extraction.

\section{Determination of alginate purity}

Alginic acid powder purity was analyzed by determining the uronic acid content according to the Blumenkrantz \& Asboe-Hansen (1973) protocol, as modified by Tullia et al. (1991). This method consists of several steps. First, concentrated sulfuric acid action leads to hydrolysis of osidic bonds and dehydration of the released monosaccharides, resulting in derived furfural compounds formation. Uronic acids react with 3-phenylphenol resulting in a pink coloration which intensity is measured by means of spectrophotometry (at $525 \mathrm{~nm}$ ). Coloration is enhanced by borate addition and interferences due to neutral sugars are minimized thanks to sulfamate (added before acid hydrolysis). .Purity was calculated as the ratio of the dry weight of uronic acids quantified to the dry weight of alginic acid powder used for the quantification.

Rheological characterisation

Intrinsic viscosity for the different samples was assessed by means of capillary viscosimetry. The elution time for each sample was measured for different dilutions in a $0.44 \mathrm{~mm}$ diameter Ubbelohde capillary viscosimeter (VWR International France, Fontenay-sous-Bois, France), immersed in a heated circulating water bath ( Polystat 73 water bath provided by Fisher Bioblock Scientific, Illkirch, France) which maintained temperature at $20^{\circ} \mathrm{C}\left( \pm 0.1^{\circ} \mathrm{C}\right)$. The different dilutions of sodium alginate samples were prepared with a $0.1 \mathrm{M} \mathrm{NaCl}$ solvent. 
Reduced viscosity vs. concentration curves were drawn and intrinsic viscosity was estimated by extrapolating reduced viscosity when the concentration tends towards 0 . The model proposed by Mancini et al. (1996) was chosen to estimate the average molecular weight: $[\eta]=1,228.10^{-5} \cdot M_{w}^{0.963}$, where $[\eta]\left(\mathrm{L}^{-g^{-1}}\right)$ is the intrinsic viscosity and $M_{w}(\mathrm{Da})$ is the average molecular weight. Besides batch and reactive extrusion samples, rheological characterization has been conducted on a commercial alginate, obtained from Sigma-Aldrich Chemie S.A.R.L., Saint-Quentin Fallavier, France (alginic acid, sodium salt - 180947-100G)

\section{Results and discussion}

The study of the reactive extrusion process for the alkaline extraction of alginates from Laminaria digitata started with a set of preliminary experiments, which enabled us to highlight specific aspects of this new process that might be of interest. It appeared that the working field was very limited, particularly concerning the ratio of algae feed rate $\left(Q_{a}\right)$ to reactive solution feed rate $\left(Q_{s}\right)$. It was then decided to conduct a series of experiments with fixed values of feed rates and screw speed $(\mathrm{N}): \mathrm{Q}_{\mathrm{a}}=1 \mathrm{~kg} \cdot \mathrm{h}^{-1}, \mathrm{Q}_{\mathrm{s}}=1 \mathrm{~L} \cdot \mathrm{h}^{-1}$ and $\mathrm{N}=400 \mathrm{rpm}$.

In order to compare the batch process with the reactive extrusion process for the alkaline extraction of alginate from Laminaria digitata, significant criteria had to be identified: extraction yield, water consumption, reactant consumption and product quality - i.e. purity and rheological properties of the product - were chosen. Both batch and reactive extrusion experiments were conducted with the aim of maximizing extraction yield. Hence, the results presented in Table 1 correspond to minimum values for water and reactant consumption enabling the maximum extraction yield to be attained.

An important advantage provided by the reactive extrusion process was huge savings in the process time: reaction time was decreased from an hour to just a few minutes. Moreover, the extraction yield was more than $15 \%$ higher than that obtained using the batch process (relative enhancement). Water and reactant consumption were both significantly reduced to less than half the consumption values recorded for the batch process. Alginic acid powder purity was equivalent for both batch and reactive extrusion processes, with values being always higher than, or equal to, 95\%. Rheological properties of alginates from both processes were studied by determining their intrinsic viscosity, which is directly linked to the average molecular weight. Reduced viscosity vs. concentration curves for alginates from batch and reactive extrusion processes, and of a high viscosity commercial alginate are displayed in Figure 2. Alginates extracted by reactive extrusion clearly have superior rheological characteristics, as high viscosity solutions can be obtained at low concentrations. Besides saving

time, this is the key advantage of the new process. These results are confirmed by intrinsic viscosity and average molecular weight values (Table 2): reactive extrusion yields alginates with chains that are almost 3 times longer than those produced using batch process. This may partly explain the enhanced extraction yield, as precipitation is more efficient with longer molecular chains.

All these enhancements may be due to the high level of shearing and mixing efficacity of the twin-screw extrusion process: algae pieces are destructured and mixed thoroughly with the reactant, so reducing considerably the time, water and reactant requirements. Reducing the reaction time helps reduce depolymerization phenomena, and consequently an alginate of high rheological quality may be obtained.

\section{Conclusion}

The purpose of this study was to evaluate the possibility of extracting alginates by reactive extrusion rather than by batch process. Even if batch experiments have been conducted at a laboratory scale, stirring conditions and algae pieces size adopted enabled to get a quite 
good simulation of industrial scale extractions. Results show that the reactive extrusion process is more efficient than the batch process for the alkaline extraction of alginates from Laminaria digitata in several key ways: time, water and reactant requirements, extraction yield and rheological properties are enhanced, whilst the purity of the product remains high. Moreover, reactive extrusion has the advantage of being a continuous process. This makes the reactive extrusion process for alginate extraction interesting both economically and environmentally. The equipment cost may be a drawback for mass production of alginates by reactive extrusion as compared with the batch process, but it could be a promising alternative for the production of high quality alginates. This preliminary study needs to be completed by optimization and costs studies (equipment and energy). The efficiency of reactive extrusion should also be tested for extracting alginate from other algae species, and for extracting other phycocolloids, agars and carrageenans.

\section{References}

Blumenkrantz N \& Asboe-Hansen G (1973) New method for quantitative determination of uronic acids. Analytical Biochemistry, 54, 484-489.

Kennedy JF \& Bradshaw IJ (1984) A rapid method for the assay of alginates in solution using polyhexamethylenebiguanidium chloride. British Polymer Journal, 16, 95-101.

Kloareg B \& Quatrano RS (1988) Structure of the cell walls of marine algae and ecophysiological functions of the matrix polysaccharides. Oceanography and Marine Biology: an Annual Review, 26 , 259-315.

Mancini M, Moresi M \& Sappino F (1996) Rheological behaviour of aqueous dispersions of algal sodium alginates. Journal of Food Engineering, 28, 283-295.

Moen E, Larsen B \& Ostgaard K (1997) Aerobic microbial degradation of alginate in Laminaria hyperborea stipes containing different levels of polyphenols. Journal of Applied Phycology, 9, 45-54.

Pérez R (1970) Teneur en acide alginique et degré de polymérisation de ce produit au cours de la vie de Laminaria digitata (L.) Lamour. Revue des Travaux de I'Institut des Pêches Maritimes, 34, 351-361.

Pérez R, Kaas R, Campello F, Arbault S \& Barbaroux O (1992) La culture des algues marines dans le monde. IFREMER, Plouzané, France.

Pérez R (1997) Ces algues qui nous entourent. Conception actuelle, rôle dans la biosphère, utilisations, culture. IFREMER, Plouzané, France.

Smidsrød O, Haug A \& Larsen B (1963) The influence of reducing compounds on the rate of degradation of alginates. Acta Chemica Scandinavia, 17, 1473-1474.

Tullia M, Filisetti-Cozzi CC \& Carpita NC (1991) Measurement of uronic acids without interference from neutral sugars. Analytical Biochemistry, 197, 157-162.

\section{Tables}

Table 1. Comparison of batch process and reactive extrusion process for the alkaline extraction of alginates from Laminaria digitata. Average values of triplicates.

\begin{tabular}{|c|c|c|c|c|c|}
\hline Process type & $\begin{array}{l}\text { Extraction } \\
\text { yield (\%) with } \\
95 \% \\
\text { confidence } \\
\text { bounds }\end{array}$ & $\begin{array}{l}\mathrm{Na}_{2} \mathrm{CO}_{3} \\
\text { consumption } \\
\left(\mathrm{kg} \cdot \mathrm{kg}^{-1} \text { dry }\right. \\
\text { algae) }\end{array}$ & $\begin{array}{l}\text { Water } \\
\text { consumption } \\
\left(\mathrm{L} . \mathrm{kg}^{-1} \text { dry }\right. \\
\text { algae) }\end{array}$ & $\begin{array}{l}\text { Time required } \\
(\min )\end{array}$ & $\begin{array}{l}\text { Alginic acid } \\
\text { powder purity } \\
\text { (\%) with } 95 \% \\
\text { confidence } \\
\text { bounds }\end{array}$ \\
\hline Batch & $33 \pm 2$ & 0.5 & 25 & 60 & $97 \pm 1$ \\
\hline $\begin{array}{l}\text { Reactive } \\
\text { extrusion }\end{array}$ & $39 \pm 2$ & 0.2 & 10 & 5 & $96 \pm 1$ \\
\hline
\end{tabular}


Table 2. Intrinsic viscosity and average molecular weight of high viscosity commercial sodium alginate and sodium alginate produced by batch and reactive extrusion extractions.

\begin{tabular}{|c|c|c|}
\hline \multirow[t]{2}{*}{ Sodium alginate type } & Intrinsic viscosity & \multirow{2}{*}{$\begin{array}{l}\text { Average molecular weight } \\
\text { (Da) with } 95 \% \text { confidence }\end{array}$} \\
\hline & $\begin{array}{l}\left({\mathrm{L} . \mathrm{g}^{-1}}^{-}\right) \text {with } 95 \% \text { confidence } \\
\text { bounds }\end{array}$ & \\
\hline $\begin{array}{l}\text { Commercial product } \\
\text { (High viscosity) }\end{array}$ & $0.12 \pm 0.02$ & $(15 \pm 3) \cdot 10^{3}$ \\
\hline Batch extraction & $0.30 \pm 0.05$ & $(36 \pm 6) \cdot 10^{3}$ \\
\hline Reactive extrusion extraction & $0.8 \pm 0.1$ & $(105 \pm 1) \cdot 10^{3}$ \\
\hline
\end{tabular}

\section{Figures}

Figure 1. Screw profile. Screw elements nomenclature : letters correspond to the screw element type and numbers correspond to the element length and pitch. T2F=trapezoid groove transfer elements (direct pitch); $\mathrm{C} 2 \mathrm{~F}=\mathrm{U}$ groove transfer elements (direct pitch); $\mathrm{C} 2 \mathrm{FC}=\mathrm{U}$ groove reverse pitch element; 100/50=100 mm long element with a $50 \mathrm{~mm}$ pitch.

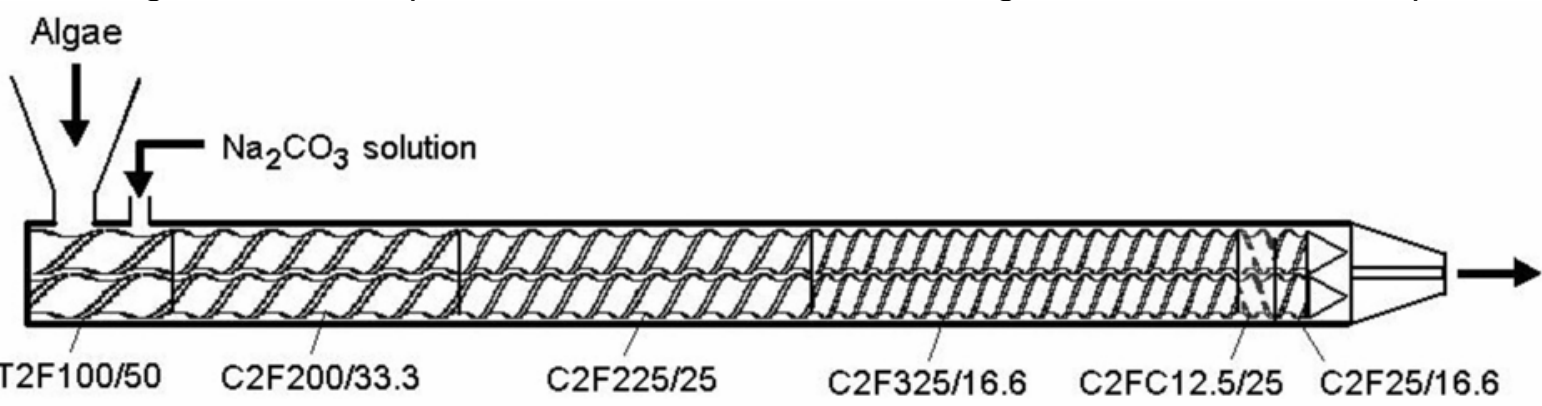

Figure 2. Reduced viscosity vs. concentration for $(\Delta)$ high viscosity commercial sodium alginate, $(O)$ sodium alginate produced by batch extraction and $(\square)$ sodium alginate produced by reactive extrusion extraction. Linear correlations are represented as a solid line.

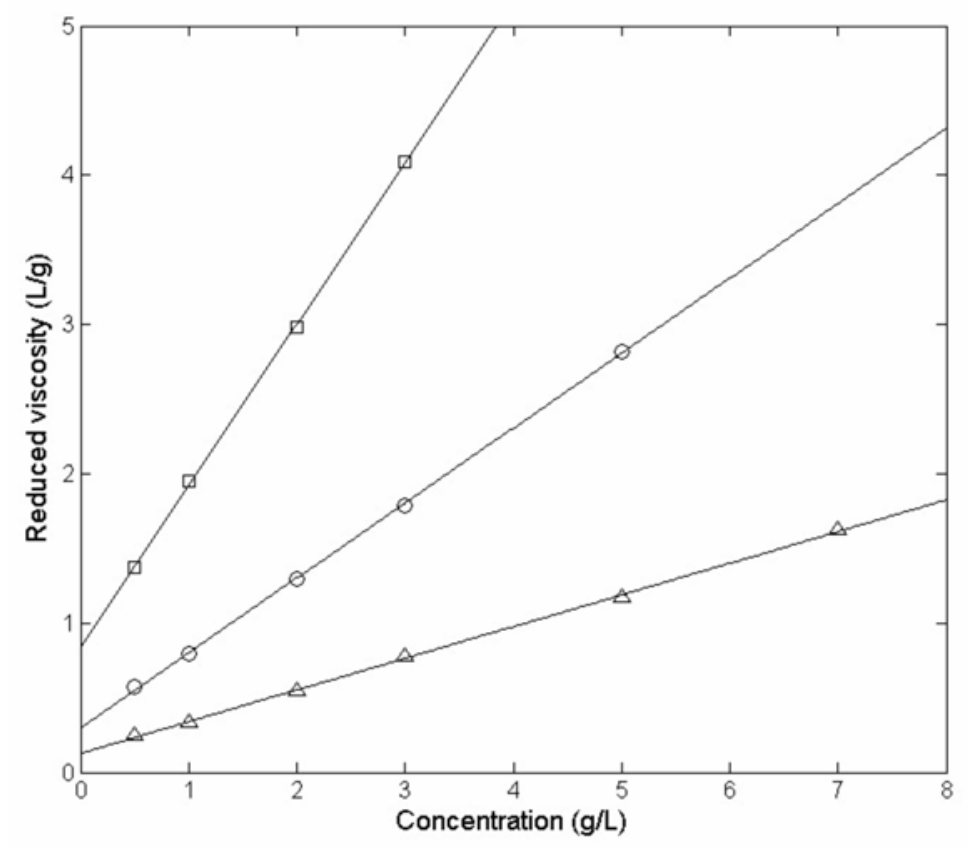

